\title{
Pesquisa clínica em saúde mental: o ponto de vista dos usuários sobre a experiência de ouvir vozes
}

\author{
Nuria Malajovich Muñoz \\ Pólo Universitário de Rio das Ostras (Universidade Federal Fluminense) \\ Octavio Domont de Serpa Jr \\ Universidade Federal do Rio de Janeiro \\ Erotildes Maria Leal \\ Universidade Federal do Rio de Janeiro \\ Universidade Estadual de Campinas \\ Catarina Magalhães Dahl \\ Universidade Estadual de Campinas \\ Iraneide Castro de Oliveira \\ Universidade Federal do Rio de Janeiro
}

\begin{abstract}
Resumo
Trata-se de pesquisa clínica acerca da experiência de ouvir vozes, centrada na análise do funcionamento de um grupo de ouvidores de vozes em um Centro de Atenção Psicossocial (CAPS). Verificamos que o exercício de construção de narrativas sobre o ouvir vozes aplicado em um dispositivo grupal produz como efeito um aumento do engajamento dos participantes nos desafios decorrentes de seu adoecimento, auxiliando na criação de alternativas que promovam a sustentação do cotidiano. O grupo se assevera, consequentemente, como um meio profícuo de avançar, coletivamente, na elaboração de soluções singulares e de criar uma comunidade de trabalho voltada para uma experiência que se caracteriza essencialmente por não ser passível de ser compartilhada.
\end{abstract}

Palavras-chave: ouvir vozes; Saúde Mental; dispositivo grupal.

\begin{abstract}
Clinical research in Mental Health: the pacients 'point of view on the experience of hearing voices. This is a qualitative clinical research on the hearing voices experience, based on the analysis of a hearing-voices group functioning in a Psychosocial Care Center (CAPS). We verified that the practice of patients narratives construction about their hearing voices experiences, in a group context, provides the raise of participants engagement in coping with the challenges of the mental illness process and helping them to create alternative ways that gives support to daily life. Consequently, the group assures a proficuous way of, collectively, developing singular solutions and creating a voice-hearing network dedicated to an experience essentially characterized as not passible for being shareable.
\end{abstract}

Keywords: hearing voices; mental health; hearing-voices groups.

$\mathrm{A}$ s narrativas individuais têm sido tomadas, no campo da Saúde Mental, como forma privilegiada de acessar o ponto de vista das pessoas que vivem a experiência da psicose. No universo da pesquisa científica, observa-se, na via oposta, uma tendência em desconsiderar ou pelo menos em minimizar os relatos pessoais sobre o adoecimento psicótico, restringindo-os ao lugar secundário de mera ilustração da teoria (Geekie \& Read, 2009). Esse tipo de abordagem tende a excluir aqueles que sofrem da discussão acerca de quais os recursos mais eficientes para sobrepujar suas consequências e implicações cotidianas, assim como da elaboração e planejamento de estratégias que tornem o cumprimento da rotina menos penosa.

A prática demonstra que muitas dessas pessoas utilizam estratégias espontâneas e originais para estabelecer uma convivência apaziguada com a psicose e seus fenômenos e que estar advertido e atento a essas soluções é fundamental para o sucesso de um tratamento. Mostra, além disso, os efeitos positivos de suas contribuições para aqueles que ainda vivem a experiência de forma muito angustiante e pouco sistematizada. Ampliar o conhecimento acerca das soluções individuais encontradas por esses sujeitos para regular as relações com o mundo e mapear os contratempos com os quais costumam 
esbarrar, são pontos essenciais, portanto, para a formalização de um cuidado mais individualizado.

Pretendemos, neste artigo, demonstrar como, através de pesquisa realizada junto a pessoas que ouvem vozes, pudemos rever e compreender como cada sujeito assimila e insere esse fenômeno em sua existência. Articularemos alguns achados de pesquisa à teoria psicanalítica da psicose de modo a demonstrar que a pluralidade de formas de apresentação da vivência não é causada por uma incapacidade pessoal em descrever o fenômeno, e muito menos por uma dificuldade de precisar a que campo sensorial as vivências se referem, mas deve ser posto em continuidade com o modo próprio pelo qual a linguagem se estrutura.

Nossa pesquisa foi inspirada no trabalho de Marius Romme, psiquiatra holandês, que desenvolveu uma tecnologia inovadora de cuidado para pessoas que ouvem vozes a partir do encontro, e em parceria, com uma de suas pacientes (Romme, Escher, Zagalo-Cardoso, \& Cunha-Oliveira, 1997). Ao introduzir a possibilidade de compartilhar esse tipo de vivência em um coletivo, apostou na capacidade dos grupos de produzirem uma melhor convivência com as vozes, estimulando a troca de experiências e a produção de narrativas pessoais sobre o assunto. $\mathrm{O}$ pioneirismo de sua abordagem diz respeito à possibilidade de considerar as vozes não como uma expressão natural de um processo de adoecimento, mas em um contexto mais amplo da vida, como uma experiência subjetiva própria à condição humana (Vasconcelos, 2003).

É importante lembrar que a experiência de ouvir vozes pode ser muito dolorosa, perturbadora ou até mesmo desesperadora. A ideia bastante difundida de que os profissionais de saúde têm como objetivo a erradicação das vozes, aliado ao fato de que o fenômeno não costuma ser visto socialmente de forma positiva em nossa cultura, pode estimular o isolamento e tornar a vivência do processo muito solitária. Apoiar e acolher essas pessoas em seu sofrimento é um passo importante na construção de modos de cuidado mais humanos, contribuindo para mudar a forma como a sociedade trata essa dimensão.

Os grupos de ouvidores de vozes partem da consideração de que o problema principal não reside no fato de ouvir vozes, mas na dificuldade de estabelecer algum tipo de convivência com elas. Essa abordagem constitui uma alternativa ao saber psiquiátrico acerca da alucinação auditiva verbal. Diferentemente do enfoque psicopatológico tradicional que privilegia o ponto de vista de um observador externo diante do fenômeno, nossa proposta inclui e valoriza a incidência subjetiva da vivência e acompanha seus desdobramentos na relação do sujeito com o mundo. A audição de vozes não é encarada como a expressão natural de um processo de adoecimento, mas na pluralidade de formas e modos como se manifesta.

\section{Método}

Nossa pesquisa se insere em um projeto mais amplo que tem por objetivo o desenvolvimento de uma abordagem psicopatológica que valorize a dimensão daquele que tem a vivência do sintoma, entendendo que sua utilização pode constituir um recurso eficiente para o aumento do empoderamento de pessoas com alucinação auditiva verbal em serviços de saúde territoriais da rede pública de assistência. Visamos possibilitar a troca de experiências entre pessoas que ouvem vozes, apostando que a circulação da palavra pode incentivar a construção de novas narrativas sobre o fenômeno.

Descreveremos, no presente trabalho, o desenvolvimento de uma pesquisa, de cunho empírico, realizada em um Centro de Atenção Psicossocial (CAPS) da rede pública de saúde do município do Rio de Janeiro. Trata-se de um estudo de caso que toma a implementação e o acompanhamento de um grupo de ouvidores de vozes como objeto, utilizando-se de metodologia qualitativa para abordar o fenômeno de ouvir vozes dentro do seu contexto de vida real, isto é, levando em consideração a relação intrincada e os limites pouco definidos entre o fenômeno e o seu contexto (Yin, 2005). Vale ressaltar que este tipo de pesquisa lida geralmente com múltiplas variáveis de interesse e é baseada em várias fontes de evidências, valendo-se do desenvolvimento prévio de proposições teóricas para conduzir a coleta e a análise de dados.

O estudo aqui apresentado permite testar as formulações psicanalíticas da psicose e se presta como possibilidade de observar e analisar um fenômeno geralmente inacessível à investigação científica, no caso, o vivido subjetivo, tão ausente da pesquisa em psicopatologia nas duas últimas décadas. Vale destacar ainda que as normas ético-científicas para a realização de pesquisa com seres humanos foram observadas seguindo a Resolução 196 de 10 de outubro de 1996 do Conselho Nacional de Saúde, tendo o projeto sido aprovado pelo Comitê de Ética em Pesquisa do Instituto Municipal de Assistência à Saúde Juliano Moreira. Foram explicados os objetivos desse dispositivo clínico a todos os participantes e fornecidas informações sobre a pesquisa. Para assegurar a privacidade e o sigilo das informações fornecidas pelos sujeitos, foram utilizados pseudônimos. Os grupos foram organizados e dirigidos por pesquisadores que atuam na área da saúde mental com as respectivas funções de coordenação, realizando a maioria das intervenções, observação da dinâmica do grupo e dos aspectos não verbais e, por fim, registro dos encontros.

A reflexão realizada acerca da função desse tipo de dispositivo para pessoas com problemas de saúde mental tomou as narrativas produzidas nesses encontros como peças de um processo aberto, sujeito a novas formulações, e ativo, resultante do engajamento de cada sujeito com o mundo. Ligar a eclosão da psicose a determinadas circunstâncias de vida ou a eventos específicos experimentados em determinado contexto constituiu, em nossa experiência, uma forma profícua de dar sentido ao vivido e conectá-lo a uma história de vida. Nessa via, podemos afirmar que a dimensão do narrar não esteve disjunta da experiência: embora sejam elementos heterogêneos, que não podem por isso ser inteiramente sobrepostos, não deixaram de tocar-se e transformar-se mutuamente.

A metodologia utilizada para a produção de narrativas tomou elementos da perspectiva psicanalítica acerca da construção de caso clínico (Figueiredo, 2004; Viganó, 1999) e que se baseiam na coleta da história dos sujeitos e de seu adoecimento tentando discernir os fatores envolvidos em seu desencadeamento, buscando reconhecer os riscos de descompensação, os pontos de 
repetição, os tratamentos realizados, assim como as alternativas utilizadas para sobrepujar o sofrimento. Esses temas foram levantados ao longo dos encontros sem fazer uso de um roteiro estruturado ou previamente elaborado, mas como uma forma de iniciar o debate ou lançar a discussão entre os participantes e visando testar com os sujeitos a possibilidade de inserir as vivências relatadas em uma perspectiva temporal, de modo a tentar estabelecer continuidades e rupturas entre a emergência das vozes e a história de vida, permitindo a sua inclusão em uma narrativa. Sustentar a coletivização em grupo dessas experiências teve como base a ideia de que o contato com universos discursivos polifônicos pudesse trazer novas perspectivas e concepções para os participantes ajudando a produzir pontos de vista inovadores (Miller, 2003a). A circulação da palavra foi sustentada dentro do dispositivo grupal garantindo, assim, a possibilidade de que novos olhares pudessem emergir a partir do convite à fala e que novos efeitos de saber se produzissem a partir do diálogo com pessoas que compartilham a mesma experiência.

Em relação à implantação do dispositivo, o projeto foi primeiramente apresentado para a equipe técnica, aos pacientes e seus familiares, em reunião regular da grade de atividades, discutindo os seus objetivos, metodologia e critérios de entrada. Ao longo do período no qual o grupo funcionou ocorreram discussões clínicas com a equipe técnica sobre os encontros, impasses e avanços experimentados no trabalho.

Os encaminhamentos para a participação no grupo foram acompanhados de discussões de casos entre os técnicos de referência e os pesquisadores responsáveis, tendo sido definidos os seguintes modos de entrada de usuários no dispositivo: 1) que ouviam vozes e queriam compartilhar esta experiência; 2) que diziam não ouvir vozes, ou que diziam ter parado de escutá-las, mas que manifestavam desejo em participar da atividade; 3 ) que apresentavam outras alterações na esfera da sensopercepção (alucinações visuais, cenestésicas, etc.) e que manifestavam desejo em participar da atividade; 4) encaminhados por outros técnicos, por apresentarem a vivência de ouvir vozes e que poderiam se beneficiar da abordagem; 5) em crise ou em internação psiquiátrica, mas com indicação de permanecer um período no CAPS e que aceitaram o convite para participar da atividade.

Apresentaremos a seguir a análise do material obtido através do registro e transcrição escrita de 26 encontros semanais, com duração de uma hora e meia cada, em um período de dezoito meses. Vale frisar que os grupos se constituíram como grupos abertos e rotativos e não tiveram nenhum protocolo de intervenção pré-estabelecido. Visou-se assim possibilitar uma ampla circulação dos usuários do serviço no dispositivo, sem exigir a sua presença, continuidade ou assiduidade. Essa liberdade de participação teve como propósito manter o convite sempre aberto a todos aqueles que desejassem participar, mesmo que pontualmente. Objetivamos, assim, dar ao grupo um caráter de oficina, encorajando a confecção de narrativas singulares e aproximando os usuários do trabalho do pesquisador, ou seja, dando condições para que estes pudessem se fazer sujeitos de sua experiência e nos acompanhar na construção de hipóteses e análise dos dados.

\section{Resultados e discussão}

A média de participação foi de seis usuários por encontro, tendo passado um total de 38 participantes pelo grupo. A distribuição quanto ao sexo foi de 12 participantes do sexo feminino e 26 participantes do sexo masculino. Mais da metade dos participantes (25) possuía diagnóstico de esquizofrenia, segundo o CID 10, registrado em seu prontuário e idade entre 19 e 45 anos (20). Gostaríamos de salientar apenas que a flutuação encontrada no modo de participação dos usuários já era esperada pela própria característica do grupo de não ser um dispositivo fechado ou com limite de participação, além de ser realizado em um serviço aberto e sem contratos de frequência rigidamente estabelecidos, favorecendo a ampla circulação de pessoas pelo dispositivo sem prejuízo para o grupo e para os usuários.

Descreveremos, a seguir, a partir de recortes de registros dos grupos, como se deu a tarefa de produção de narrativas com pessoas cuja relação com a linguagem se apresenta de forma singular e diferenciada, sinalizando as estratégias utilizadas e os efeitos alcançados. Queremos, assim, problematizar a função que o trabalho de fala pode ter na psicose e destacar a importância do dispositivo grupal para a realização desse propósito. $\mathrm{O}$ estabelecimento de continuidades e rupturas entre a emergência do fenômeno de ouvir vozes e a história de vida dos sujeitos constituiu um elemento chave para a sua possível inclusão em uma narrativa pessoal.

\section{Uma relação particularizada com a linguagem}

Embora prescinda de uma organização prévia, não é possível afirmar que a linguagem não opere na psicose. A psicose é pensada, na psicanálise, por contraste à neurose, como aquela modalidade clínica que prescindiria de uma operação central para a estruturação da subjetividade. Se a função paterna está para a neurose no "anel que faz manter-se tudo junto" (Lacan, 19551956/1985, p. 358), a psicose estaria, pela falta desse atributo, mais exposta a experimentar o desenlace de seu campo. Em contrapartida, a falta de um elo fixador dispensaria o sujeito de ter de percorrer a previsível via padrão, tornando-o mais livre para acessar e inventar os seus pequenos caminhos individuais. Cabe aos sujeitos psicóticos a difícil tarefa de construir os seus próprios anéis através de materiais reciclados da cultura, transformando esses artefatos inusitados em formas de suprir e sustentar a relação com o mundo.

O surto psicótico evidencia a falência da lei que organizaria a linguagem, ocasião na qual se passa da categoria de habitante à difícil posição de ser por ela habitado (Lacan, 1955-1956/1985). As vozes podem se apresentar com um caráter fora do sentido, desarticulado do senso comum, ocasião na qual costumam se tornar angustiantes e penosas. Ao prescindir da via padrão, o psicótico precisa então recorrer a um artifício próprio para se localizar no mundo. É no meio de um mar de palavras e frases desconexas que um elemento novo e não atrelado à norma fálica deverá ser acrescido de forma a possibilitar que o sujeito possa conquistar um lugar na linguagem (Lacan, 1957-1958/1998b). A produção de modos de amarração originais exige um "se deixar levar" para além das convenções estabelecidas pelo código da língua. A direção de trabalho seguiu, nessa orientação, 
incentivando e apostando na circulação de pequenos saberes, em detrimento de um saber totalizador e sem furo.

Roberto diz que se vê muitas vezes como objeto na ausência de "uma lei, de um meio censurado" que o tire do vazio ao qual está submetido e de onde emergem vozes que "veiculam conteúdos através de símbolos e frases incompletas". Joaquim descreve a experiência como "uma desconexão, um corpo se movimentando em um imenso vazio". Kátia tenta cuidadosamente estabelecer o percurso efetuado por suas vozes em seu corpo mostrando a variação sofrida ao longo de sua jornada:

Antigamente elas vinham de fora pra dentro. Só depois é que passaram a vir de dentro pra fora. Costumavam vir de dentro da janela. Agora elas vêm da minha mente, parece que (...) é como se eu estivesse oca. Quando perturbam muito, você acaba perdendo a memória. Fica difícil retomar os sentidos.

A alucinação é considerada, para a psicanálise, como resultante de um modo particular de inserção na linguagem. Freud (1911/1989) chegou a se perguntar se as vozes que acometem pessoas com esquizofrenia poderiam ser consideradas como uma tentativa de cura ou como um processo de adoecimento. Tendeu, curiosamente, a considerá-las em sua primeira vertente, sugerindo que o fenômeno possibilitaria a exteriorização de um processo que tenderia, do outro modo, a se passar inteiramente no nível do corpo.

As vozes podem ser postas, assim, em continuidade com outras vivências mais amplas, refletindo as consequências de uma relação diferenciada com o mundo. Quanto mais a linguagem se encontrar desarticulada, mais o sujeito tenderá a viver as alterações decorrentes de sua estruturação em termos corporais. A perspectiva de um tratamento da linguagem produz efeitos inclusive na sustentação do corpo enquanto unidade e repousa na consideração de que os significantes, mesmo que desconexos, funcionam como matéria a ser utilizada na construção de lugares possíveis para o sujeito no mundo.

\section{Compartilhando uma experiência plural}

A categoria leiga "ouvir vozes" abarca uma ampla gama de experiências, dentre as quais algumas de difícil elaboração, produtoras de estranhamento, que não estão comumente associadas àquilo que a psiquiatria costuma chamar de alucinação auditiva. Isso significa que não necessariamente a percepção de ouvir uma voz que fala de fora da cabeça precisa estar presente para que o sujeito se auto atribua a experiência de ouvir vozes. Alguns sentem que a televisão se dirige a eles, outros relatam essa experiência como um "não conseguir parar de falar sozinho", outro diz "ouvir vultos", "uma mosca conversando", "um repuxamento do lado esquerdo", "uma mão quente no ombro", "balas passando pela corrente sanguínea", um "não se reconhecer no espelho", para citar alguns exemplos.

O saber leigo aproxima-se então daquilo que Lacan (19621963/2005) conceituou como voz e que não deve ser pensado em termos de sonoridade. A voz se caracteriza por não poder ser definida pela palavra, mas por também não poder ser incluída em nenhum processo que tenha relação com a atividade de falar (Miller, 1997a). A voz é uma dimensão própria à estrutura da linguagem, constituinte do universo simbólico que é paradoxalmente muda, não falante, e diz respeito ao indizível. É parte da cadeia significante e, enquanto ausência, possibilita a atribuição subjetiva, fazendo o sujeito existir. Falar em nome próprio é, então, na neurose, uma forma de calar a voz.

A estabilidade do campo da realidade se preserva a partir da extração de um elemento de seu campo. A esse vazio, Lacan (1962-1963/2005) dá o nome de objeto a, "libra de carne" (p. 242) sacrificada, para sempre perdida no momento em que o sujeito se engaja no jogo significante. A não extração desse objeto provoca, em contrapartida, uma não separação do campo do Outro, da linguagem, tornando a realidade instável e fazendo com que a voz, enquanto objeto impossível de dizer, seja passível de ser desvelada.

A voz ganha assim o estatuto de objeto que retorna na psicose e não pode por isso ser totalmente separada do sujeito que a alucina (Lacan 1964/1973). A voz inaudível muitas vezes se apresenta como uma experiência corporificada de uma presença externa. $\mathrm{O}$ modo como o sujeito vivencia o retorno de conteúdos expulsos do Simbólico no Real se exemplifica na função ocupada por Deus para Schreber: "Ele é em primeiro lugar presença. E seu modo de presença é o modo falante" (Lacan, 1955-1956/1985, p. 146). A voz ganha uma exterioridade radical e ao mesmo tempo se dirige ao sujeito, podendo se expressar sob o modo falante, mas também escrito, lido ou ainda sentido. Se a alucinação é verbal, efeito de uma relação particular com o significante, torna-se preciso fazer uma distinção entre a presença da voz no Real e o conteúdo das vozes - que pode estar presente ou ausente - resposta e, por isso, tentativa de cura, do sujeito ao enigma que se impõe a ele por essa pura presença.

Explicitaremos essa dimensão da voz, através de um fato, extraído de nossa experiência com o dispositivo grupal, que nos fez experimentar os efeitos da tagarelice da linguagem no coletivo. Alguns encontros foram tomados pelo atravessamento de um zumbido crescente: impulsionados pela discussão, os participantes se lançavam em um falatório incessante, surdo e sem endereçamento. A imagem de uma orquestra desencontrada em sua polifonia ilustra o efeito desta mussitação coletiva. Esse dado clínico nos fez compreender que a dimensão mais fundamental da voz é aquela que revela o objeto como puro resto, dejeto do mundo, lixo que atravanca, mas que aponta a presença de vida humana, mesmo que o seu autor não seja, na ocasião, passível de ser localizado.

O caráter individual e intransponível da voz a torna sempre única e não idêntica à de um outro ouvidor de vozes. Como então coletivizar essa experiência? Como compartilhar sem se identificar com a experiência do outro? Uma manobra clínica é exigida de modo a dar coletivamente crédito a todas as vozes narradas, realizando, por exemplo, aproximações e rupturas entre as diferentes experiências descritas. Há uma tendência em não se identificar com a vivência do outro ("no meu caso é diferente") ou até em desqualificá-la ("não é voz, é pensamento. Ricardo [um outro participante] é que não sabe reconhecer”). $\mathrm{O}$ vivido alucinatório não provoca comunhão, é uma experiência radicalmente particular. Mas, paradoxalmente, esse pretenso problema ganha aqui o estatuto de solução: a incompatibilidade impede a cola grupal, o grude imaginário entre os seus membros. 
Torna possível, ao se demarcar e positivar a diferença, o intercâmbio, a troca, o diálogo: ao não se tratar do igual, abre-se a possibilidade de fazer existir a dimensão do semelhante. Essa dimensão introduz uma distância necessária que possibilita olhar para o outro enquanto outro e, ao mesmo tempo, força o sujeito a se separar um pouco de suas vozes. É importante frisar que a voz vem de fora, mas concerne ao sujeito em seu ser. Não se trata, assim, de um possível erro de pensamento ou de um déficit na apreensão da realidade. O que está em questão nos fenômenos psicóticos, sejam eles alucinações, interpretações ou intuições, não é a realidade, a crença ou a sensorialidade que o sujeito lhes confere, mas o fato de que estes "o visam pessoalmente" (Lacan, 1946/1998a, p.166). O trabalho de construção das narrativas não deve insistir, por isso, na diferenciação ou aproximação entre as experiências, mas enfatizar a possibilidade de cada um traduzir a sua. Ao inserir o fenômeno de audição de vozes no campo da linguagem abre-se a possibilidade de tratá-la em um exercício de fala.

\section{O dito espirituoso: um artifício para habitar a lin- guagem?}

Compartilhar as vozes e seus efeitos em grupo pode ser útil para contornar o caráter fora do sentido da experiência, ao introduzir múltiplas e novas formas de se haver com aquilo que se apresenta como resto, desconectado do universo discursivo. A tirada espirituosa e o efeito surpresa, ao se constituírem como manobras excluídas da significação compartilhada, conferem um lugar ao nonsense na linguagem (Ribeiro, 2006). Promovem formas de nomeação daquilo que se coloca fora do sentido, viabilizando a invenção de sentido original. Sustentar essa direção provoca efeitos coletivos que favorecem inclusive aqueles que ainda se encontram muito submergidos na experiência de perplexidade. Tendo acesso ao testemunho de participantes que conseguiram estabelecer uma relação mais distanciada com as suas vozes, percebem ser possível o desenvolvimento de truques e de formas originais de lidar com a sua presença e seus aspectos mortificantes. Relataremos a seguir dois episódios onde julgamos ter se produzido um efeito de localização do não sentido.

No primeiro episódio, Laura inicia o seu depoimento contando ao grupo que sua sombra fala com ela. Por isso, refere precisar andar sempre junto com o sol (para não fazer sombra). Na semana seguinte, acrescenta que o sol também fala com ela. Não sabe precisar o quê ele fala, "é uma fala sentida no corpo, uma presença, ele está em todas as partes”. João pergunta: “e falar com a lua, você já falou?" Ela assinala que não. Então Ricardo diz: "será que existem pessoas que falam com a lua?" João responde: "Existe sim. São os lunáticos!” (e todos caem na gargalhada).

No segundo episódio, uma conversa se estabelece no grupo em torno da justeza ou não do emprego do termo 'maluco' para se referir a todo aquele que ouve vozes. Alberto defende de forma radical o uso do termo, dizendo que não liga a mínima quando assim é chamado, pois para ele o dito representa a sua verdade: considera que a sua palavra não tem valor. Justifica dizendo que faz coisas, por vezes, das quais não se lembra, como quebrar a sua casa inteira e que isso é fruto da "tentação". Toma então a palavra Francisco, usuário do CAPS cuja fala tende sempre a ser muito desconexa e desorganizada e que pouco participa das conversas no grupo. Perplexos, o assistimos pontuar que se "de médico e de louco todo mundo tem um pouco", ele gostaria que sua palavra tivesse valor e diz, inclusive, ter um forte desejo de poder transmitir seus ideais. Passados alguns instantes de silêncio admirativo, Alberto aquiesce e, pensativo, endereça a seguinte questão ao coletivo: "como é que então a gente faz para não obedecer às vozes?”, redirecionando a sua posição.

O caráter inovador desse dispositivo repousa no fato de disponibilizar o material produzido pelos ouvidores de vozes em um coletivo, de modo a possibilitar usos particulares daquilo que retorna desde fora para cada um. Uma espécie de oficina de reciclagem do lixo que retorna do Real. A constituição de um laço entre os participantes permitiu inclusive acolher a crise, com intervenções desenhadas pelo sujeito e pelo grupo. Aristides, ouvidor de vozes há 30 anos, indicou a Lucas, jovem ouvidor que passava por um momento de muita angústia e tendia a considerar a experiência negativa, querendo erradicá-la: "Presta atenção garoto, porque a gente reclama das vozes, mas o problema é que quando elas somem, deixam saudade".

Os estilhaços produzidos pelo encontro explosivo do sujeito com a alteridade constituem restos e sobras que, ao serem recolhidos no dispositivo grupal, permitem que os ouvidores de vozes lhes deem um novo uso que pode, por sua vez, apaziguar a produção alucinatória. Apoiado pelo dispositivo grupal, Adolfo decide conversar com suas vozes, utilizando-se de uma teoria explicativa particular. Em determinado ponto de sua trajetória interpreta que os xingamentos proferidos pelas vozes acontecem em resposta ao fato dele nunca lhes responder quando falam. Decide mudar a sua atitude e ao invés de ignorá-las passa a tratá-las com paciência e polidez: "Mas que falta de educação! As vozes falavam e eu não respondia, que indelicadeza! Agora, quando elas começam a xingar, digo a elas que não precisam se ofender, que já vou lhes dar atenção, etc".

João Pedro também criou uma solução para minimizar o sofrimento causado pelo conteúdo de suas vozes:

As vozes me diziam que a mulher de $\mathrm{X}$ [uma pessoa de sua família] estava interessada em mim, que ela me amava, que ela ia largá-lo para ficar comigo. Eu dizia que isso era mentira, que ela era moça direita. Chegou uma hora em que pensei em me matar ou em matar ela, não aguentava mais. As vozes insistiam, diziam que elas sabiam de tudo, que eram donas da verdade. Um dia eu me cansei de ouvir essas calunias e foi aí que eu tive uma idéia. Disse a elas que já que elas diziam que sabiam tudo, então eu queria que elas me dissessem quais iam ser os números sorteados na loteria. Então fui e comprei o bilhete, porque pensei que, sei lá e se elas estiverem certas? Mas aí elas erraram! Confesso que nunca fiquei tão satisfeito de ter perdido.

O trabalho clínico permite a obtenção de um saber por parte dos sujeitos mapeando algumas coordenadas que podem viabilizar formas de 'se virar' com a língua. É preciso assinalar que o saber em questão não tem o estatuto de um saber inconsciente, mas de um saber fazer (Miller,1997b). O pano de fundo à nossa abordagem se centrou justamente na procura de formas eficazes de promover invenções de saber a respeito da 
experiência de ouvir vozes que respeitem e incluam o ritmo e a produção particular de cada sujeito sobre elas.

\section{Considerações finais}

Os depoimentos mostram que é possível dar um uso a esses restos, construindo um percurso a partir do que os letreiros borrados do Outro assinalam através de suas pequenas setas indicadoras (Lacan, 1957-1958/1998b). Esses exemplos mostram o que é possível de se produzir quando nos colocamos dispostos a recolher e trabalhar com os pedaços de Real que os usuários nos dão a chance de conhecer. A saída espirituosa pode ser uma arma interessante contra as investidas de gozo decorrente do desenlace do campo que compõe a linguagem. Alguns participantes manifestaram que a frequência ao dispositivo diminuiu o acossamento causado por uma escuta alucinatória incessante. Vejamos o depoimento de Jacques:

Antes eu ouvia vozes torturantes, mas agora só ouço uma ressonância de conteúdo agradável. Acho que o grupo tem me ajudado, ele me traz conforto. Acho muito importante isso de falar das vozes porque os pacientes psiquiátricos. Eles costumam ser assim muito submissos; acho que é porque eles não têm o domínio da conversa.

A voz não se manifesta apenas como dito, mas se relaciona a todo um conjunto de alterações que atestam o parasitismo da linguagem e afetam a experiência de si, dos outros e do mundo. A voz enquanto figura do sem sentido, possibilita ampliar nosso enfoque acerca dos distúrbios da linguagem e permite defini-los pelo seu caráter de perplexidade, vazio de significação que retorna no corpo e invade, desde fora, o sujeito. Essa perspectiva permite retomar a indicação freudiana de 1911 de que a alucinação poderia servir como uma tentativa de cura na esquizofrenia: ao se fazer presente enquanto significante no Real, a voz localiza em um dito exterior aquilo que costuma se passar no nível do corpo, permitindo que o sujeito possa, em um segundo tempo, dar um nome que fixe e organize a experiência.

Pelo tipo de efeito produzido pelo dispositivo, o trabalho pode ser posto como estando do lado do ofício do artífice. Ao propor novos usos para o material alucinado, permite a entrada de elementos heterogêneos que, por serem usados de forma individual por cada participante, marcam lugares singulares para cada um em relação a um coletivo. Dar voz aos que ouvem vozes é uma estratégia clínica que não está desarticulada da política, pois tem no horizonte o objetivo de disponibilizar um certo saber fazer com as vozes para todos aqueles que dele precisarem, além de coletivizar uma experiência que ainda hoje carrega o forte traço da segregação.

Os grupos de ouvidores de vozes se inscrevem assim como um dispositivo capaz de silenciar a voz tonitruante que, com a sua presença exterior, invade e marca o sujeito na psicose. Mostram a importância de depositar uma confiança na psicose e em seus fenômenos, apostando no saber leigo. Trata-se de utilizar as invenções psicóticas (Miller, 2003b) para revisar e problematizar o lugar da norma e do universal. Abre-se, assim, uma nova perspectiva clínica apoiada nas soluções, arranjos e possibilidades variadas da psicose, mostrando que existem alternativas para além daquilo que os tratamentos tradicionais preconizam. Acreditamos ter demonstrado uma forma possível de construir um cuidado que parta de soluções particulares para o enfrentamento coletivo dos fenômenos vividos.

\section{Referências}

Figueiredo, A. C. (2004). A construção do caso clínico: uma contribuição da psicanálise à psicopatologia e à saúde mental. Revista Latinoamericana de Psicopatologia Fundamental, 7(1), 75-86.

Freud, S. (1989). Notas psicanalíticas sobre um relato autobiográfico de um caso de paranóia. In S. Freud, Edição standard brasileira das obras psicológicas completas de Sigmund Freud (Vol. 12, pp. 27-108). Rio de Janeiro: Imago (Texto original publicado em 1911)

Geekie J., \& Read J. (2009). Macking sense of madness: contesting the meaning of schizophrenia. London: Routledge.

Lacan, J. (1973). Le seminaire, livre 11: les quatre concepts fondamentaux de la psychanalyse. Paris : Seuil. (Texto original publicado em 1964)

Lacan, J. (1985). O seminário, livro 3: as psicoses. Rio de Janeiro: Jorge Zahar (Texto original publicado em 1955-1956)

Lacan, J. (1998a). Formulações sobre a causalidade psíquica. In J. Lacan (Org.), Escritos (pp.152-194, V. Ribeiro, Trad.). Rio de Janeiro: Jorge Zahar (Texto original publicado em 1946)

Lacan, J. (1998b). De uma questão preliminar a todo tratamento possível da psicose. In J. Lacan (Org.), Escritos (pp.537-590, V. Ribeiro, Trad.). Rio de Janeiro: Jorge Zahar (Texto original publicado em 1957-1958)

Lacan, J. (2005). O seminário, livro 10: a angústia. Rio de Janeiro: Jorge Zahar (Texto original publicado em 1962-1963)

Miller, J. A. (1997a). Jacques Lacan y la voz. In J.A Miller (Org.), La voz (Colección Orientacion Lacaniana, pp. 9-21). Buenos Aires: Escuela de la Orientación Lacaniana.

Miller, J. A. (1997b). La Conversation d'Arcachon. Cas rares: les inclassables de la clinique. Paris: Seuil.

Miller, J. A. (2003a). La pareja y el amor. Buenos Aires: Paidós.

Miller, J. A. (2003b). A invenção psicótica. Opção Lacaniana, 36, 6-19.

Ribeiro, M. M. C. (2006). O riso na clínica das psicoses. Rio de Janeiro: 7 Letras.

Romme, M., Escher, S., Zagalo-Cardoso, J. A., \& Cunha-Oliveira, J. A. (1997). Na companhia das vozes: para uma análise da experiência de ouvir vozes. Lisboa: Estampa.

Vasconcelos, E. M. (2003). O poder que brota da dor e da opressão: empowerment, sua história, teorias e estratégias. São Paulo: Paulus.

Viganó, C. (1999). A construção do caso clínico em saúde mental. Revista Curinga, 13, 50-59.

Yin, R. K. (2005). Estudo de caso: planejamento e método (3 $3^{\underline{a}}$ ed.). Porto Alegre: Bookman. 
Nuria Malajovich Muñoz, doutora em Teoria Psicanalítica pela Universidade Federal do Rio de Janeiro, é professora Adjunta do Pólo Universitário de Rio das Ostras, Universidade Federal Fluminense. Endereço para correspondência: Rua General Glicério, 326/603, Laranjeiras, Rio de Janeiro. CEP: 22245-120. Telefones: (21) 2226-7913/(21)9254-0045. E-mail: nuria@rio.com.br

Octavio Domont de Serpa Jr, doutor em Psiquiatria e Saúde Mental pela Universidade Federal do Rio de Janeiro, e pós-doutor pelo Centre de Recherches en Epistémologie Apliquée/Ecole Polytechnique - Paris, é professor Adjunto da Universidade Federal do Rio de Janeiro e coordenador do Laboratório de Estudos e Pesquisas em Psicopatologia e Subjetividade. E-mail: domserpa@gmail.com

Erotildes Maria Leal, doutora em Ciências da Saúde pela Universidade Federal do Rio de Janeiro, e pósdoutora pela Universidade de Toronto/CICAD, é professora Adjunta da Universidade Federal do Rio de Janeiro, e professora Associada da pós-graduação em Saúde Coletiva da Faculdade de Ciências Médicas da Universidade Estadual de Campinas. E-mail: erotildesleal@macae.ufrj.br

Catarina Magalhães Dahl, especialista em Saúde Mental no nível de residência pelo Instituto de Psiquiatria da Universidade Federal do Rio de Janeiro em parceria com o Instituto Municipal de Assistência a Saúde Juliano Moreira, é Mestranda em Saúde Coletiva pela Universidade Estadual de Campinas. E-mail: catdahl@ hotmail.com

Iraneide Castro de Oliveira, especialista em Psiquiatria pelo Instituto de Psiquiatria da Universidade Federal do Rio de Janeiro, é médica do Ministério da Saúde e da Secretaria de Municipal de Saúde do Rio de Janeiro. E-mail: ira.col@uol.com.br 